\title{
-News Briefs
}

\section{BOXMAG-RAPID IN ZIMBABWE CONTRACT}

Boxmag-Rapid, the Birmingham based specialists in applied magnetics technology, has completed a contract to supply two different types of magnetic separation equipment to Bikita Minerals based in Bikita in Zimbabwe. The contract, which was valued at $£ 70000.00$ sterling, included the supply of two boxmag-Rapid Magnarolls which are high intensity rare earth permanent magnetic separators.

The second type of unit supplied was a Model HIW-1 high intensity wet electromagnetic separator. The magnetic separators are used to remove naturally occurring ferrous bearing minerals from spodumene which is the chief source if lithium. Lithium is used as an alloying element, as a catalyst and for the production of chemicals.

The Boxmag-Rapid equipment reduces the ferrous contamination to $0.05 \%$ which is half that of the current market demand. Boxmag-Rapid carried out extensive laboratory tests on samples material sent by Bikita. The tests were undertaken both in-house by Boxmag-Rapid and under contract to them by Birmingham University and Attwood Testing.

The tests undertaken by Birmingham University included $\mathrm{x}$-ray diffraction which enables identification of the iron-bearing phases present. Based on results of the tests Boxmag-Rapid recommended a two-stage process utilising the Magnaroll and HIW-1 units.

\section{NEW POWDER COMPACTION METHOD FOR MAGNETS}

Intermetallics Co. Ltd., Kyoto, Japan, a research and development venture enterprise, has developed a new mass production technique for high-performance permanent magnets, and succeeded in manufacturing $\mathrm{Nd}$ magnets with a maximum magnetic energy product of $50 \mathrm{MGOe}$, the best performance among high-strength magnets commercialized up to now.

The energy product of the strongest $\mathrm{Nd}$ magnets mass-produced today is 43 MGOe, so the newly developed magnets have the energy product greater by $19 \%$. This was achieved by the introduction of a new manufacturing method called Rubber Isostatic Pressing (RIP) employing a rubber mold in place of conventional type of metal die. Magnetic powder is packed in the rubber mold, press-hardened by impressing a strong magnetic field, then the permanent magnet is extracted from the mold and sintered. Strong magnetic field is applied to magnetise. up to now, the powder used to be packed and densified in a metal die, but with the new technology, the rubber mold is packed with the powder and the powder compressed isostatically by utilising the rubber elastic deformation. 
Using a rubber mold enables the powder to be compressed uniformly from all sides by the repulsive force of the rubber. In contrast, in a metal die the pressure is impressed only vertically so that the magnetic alignment of the powder prior to pressing is disturbed. This used to be an obstacle in the manufacture of high-performance magnets. The new manufacturing technology minimises this disturbance and improves the magnet performance considerably.

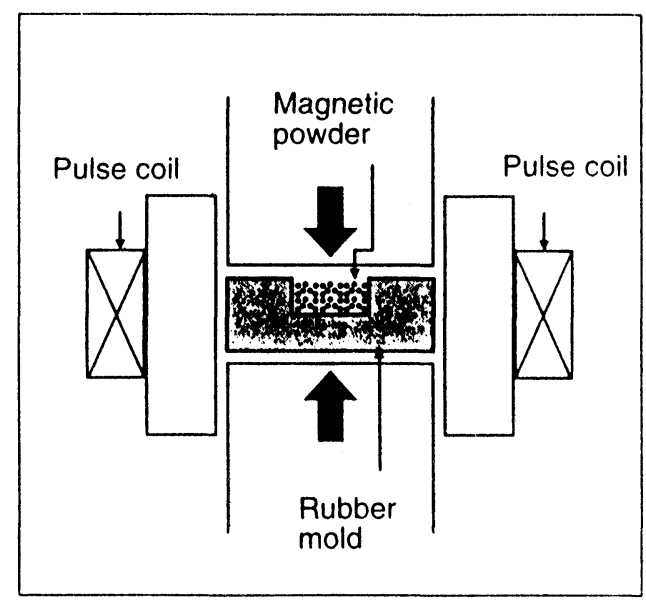

With the RIP powder compaction method, only the rubber mold is replaced in conformance with changes in the product shape and dimensions, and there is no need to replace metal dies. The cost of the rubber mold used in the RIP method is virtually negligible compared with that of metal dies. Products in small lots of about 100 units can be molded by the RIP method.

The RIP technology improves the magnetic properties not only of Nd-Fe-B magnets but also of Sm-Co magnets and ferrite magnets. By using RIP, 35 MGOe Sm-Co magnets and 5.1 MGOe ferrite magnets can be produced.

\section{MEASUREMENT OF RESIDUAL MAGNETIZATION IN ROCKS}

Dowa Mining Co. Ltd., Japan, in cooperation with the Tohoku University has developed a system for measurement of weak residual magnetization in rocks. The instrument is based on the application of a high-temperature superconducting shield. Weak magnetism in rocks is measured in a closed environment inside the magnetic shield to specify the magnetic azimuth which facilitates the discovery of underground resources such as terrestrial heat and petroleum. Compared to the existing systems, the accuracy has been increased by a factor of 100 , the instrument is compact, portable and weighs $60 \mathrm{~kg}$. The resolution of remanent magnetization is 1 nanotesla. 


\section{ROLLIN J. PARKER: 1920-1994}

Rollin J. Parker, an internationally known expert on permanent magnetism and magnetic materials died on September 13,1994. He has over 35 Us patents issued in his name, many of which are utilised in various consumer products. a native of Essex Junction, Vermont, USA, he earned his bachelor's degree in electrical engineering from the University of Vermont and a master's degree in materials science from Michigan State University. He was a 30-year employee of General Electric Co. and, from 1973 to his retirement in 1985, was a manager of advanced design and development for Hitachi Magnetics Corp.. In 1985 he founded Parker Associates, a private consulting firm specialising in the markets and applications of magnetic materials. Mr. Parker was a co-author of the 1962 book "Permanent Magnets and Their Application" and author of the 1990 book "Advances in Permanent Magnetism", both published by John Wiley \& Sons of New York. Mr. Parker was well known to rare-earth-permanent magnet researchers and producers by his expert counselling and writings on the market potential and commercial applications of rare earth permanent magnets.

\section{JAPANESE IMPORT OF RARE EARTHS RISES BY OVER 30\%}

Japanese imports of rare earths have shown a recovery in 1994 as consumers have built up stocks to meet growing demand. The increase in imports of neodymium oxides (from France, USA, China and North Korea) and fluorides (from France, China and USA) was significant. Imports of rare earths totalled Yen $3800 \mathrm{M}$ in January to September 1994, near the value of imports for the whole of 1993. Imports in terms of value are forecast to rise by $30 \%$ in 1994.

(Source: Roskill's Letter from Japan, December 1994).

\section{A SHIFT FROM Sm-Co TO Nd-Fe-B MAGNETS}

As a result of rising price of cobalt, the Japanese producers of magnets plan to shift away from the use of cobalt or to reduce the quantities they use. Producers of Alnico magnets raised their prices of cast magnets when the price of cobalt rose steeply in 1992. Since then the price of cobalt has fallen, but producers could not significantly reduce the price of magnets because of fluctuations in exchange rates. The latest rise in cobalt prices means producers of Alnico magnets are trying to increase prices. Hitachi Metals say that as they cannot raise the price of Sm-Co magnets because of competition from $\mathrm{Nd}-\mathrm{Fe}-\mathrm{B}$ magnets, they have been shifting production towards Nd products. 